\title{
Sciendo
}

Int. J. of Applied Mechanics and Engineering, 2021, vol.26, No.2, pp.201-218

DOI: $10.2478 /$ ijame-2021-0028

\section{FEM STUDY OF A STEEL CORRUGATED WEB PLATE GIRDER SUBJECTED TO FIRE}

\author{
D.SOKOLOWSKI* and M.KAMIŃSKI \\ Faculty of Civil Engineering, Architecture and Environmental Engineering \\ Łódź University of Technology, Al. Politechniki 6, 90-924 Łódź, POLAND \\ E-mail: sokolowski.dmn@gmail.com
}

\begin{abstract}
The main aim of this work is a computational nonlinear analysis of a high strength steel corrugated-web plate girder with a very detailed and realistic mesh including vertical ribs, all the fillet welds and supporting areas. The analysis is carried out to verify mechanical structural response under transient fire temperature conditions accounting for an efficiency and accuracy of three various transient coupled thermo-elastic models. All the resulting stress distributions, deformation modes and their time variations, critical loads and eigenfrequencies as well as failure times are compared in all these models. Nonlinearities include material, geometrical and contact phenomena up to the temperature fluctuations together with temperature-dependent constitutive relations for high strength steel. They result partially from steady state and transient experimental tests or from the additional designing rules included in Eurocodes. A fire scenario includes an application of the normative fire gas temperature curve on the bottom flange of the entire girder for a period of 180 minutes. It is computed using sequentially coupled thermo-elastic Finite Element Method analyses. These account for heat conductivity, radiation and convection. The FEM model consists of a combination of 3D hexahedral and tetrahedral solid finite elements and uses temperature-dependent material and physical parameters, whose values are taken after the experiments presented in Eurocodes. Numerical results presented here demonstrate a fundamental role of the lower flange in carrying fire loads according to this scenario and show a contribution of the ribs and of the welds to the strength of the entire structure.
\end{abstract}

Key words: steel structures, Finite Element Method, corrugated web plate girders, fire simulation.

\section{Introduction}

As it is known, the high strength steel plate girders with corrugated webs become systematically more and more popular in civil engineering applications due to their higher stiffness and definitely smaller sensitivity to local stability losses in the web [1] and lower weight than traditional I-beams with the same bending capacity. They are applicable as the principal bridge longitudinal girders, circular arches [2] and also as traditional beams and columns [3], yet suffer from local effects on the web, such as a sudden local shear failure [4] or the welds fatigue [5]. Corrugated webs are as well commonly used in hybrid beams with concrete flanges [6]. Despite their multiple advantages, they have some disadvantages. They cause an additional normal stress distribution in flanges coming from transverse bending [7] and offer a weaker contribution to bending [8] than the regular I-beams. The research connected to the corrugated web dates back to 1969, when Easley $[9,10]$ studied buckling of light-gauge corrugated metal shear diaphragm and further concentrated on a precise determination of a shear stress in a small-scale corrugated diaphragm. A decade later, Elgaaly et al. [11] proposed a methodology for calculating the global buckling and elastic local buckling stresses. The first studies of the girders with a corrugated web were conducted by Elgaaly and Seshadri [12], where shear and patch loading were investigated. Next, Li et al. [13] conducted experimental tests showing that a corrugated web is $1.5-2.0$ times more resistant to shear than flat web girders. In the following years, multiple shear oriented studies on corrugated web beams and girders were conducted.

\footnotetext{
${ }^{*}$ To whom correspondence should be addressed
} 
Driver et al. [14] investigated I-girders with imperfections, evidenced overestimation of shear buckling in such conditions and proposed a lower bound equation for shear. Moon et al. [15] proposed a global shear buckling coefficient, Pasternak and Kubieniec [16] discussed EN rules for designing corrugated web Ibeams and $\mathrm{He}$ et al. [17] studied numerically partially encased I-girders with different material and geometric parameters. In following years numerical analyses concentrated on shear were carried out by Hassanein and Kharoob [18], Hassein et al. [19], Leblouba et al. [20] and Riahi et al. [21], where girders with flat web and the corrugated web were investigated in a parametric study with 10 main parameters. Shear strength was also studied numerically for tapered bridge girders by Zevallos et al. [22], who observed a reduction of strength together with an increase of tapering angle. Further parametric analysis of tapered beams was performed by Elkawas et al. [23]. El Hadidy et al. [24] studied shear for corrugated web girders with tubular flanges and found that they offer higher strength and stiffness of the girders compared with the case of flat flange girders, when depth-to-width ratios of this flanges is not small. Wang et al. [25] extended the shear studies for composite beams with a joint of the corrugated web with concrete slab and Aydin et al. [3] studied behavior of the beam-to-column connection with corrugated webs. Zirakian et al. [1] studied numerically the usage of coupling corrugated web beams for energy dissipation purposes. He found that corrugated webs have a better performance in energy dissipation than flat webs. Wang et al. [26] further experimented on cyclic behavior of composite beam with corrugated web and proved that it takes around $80 \%$ of shear and could be applied for anti-seismic structure. A high research attention was also paid to bending behavior of corrugated web I-beams. A first study in this area was performed by Elgaaly et al. [11, 12], where a sudden failure was observed due to vertical buckling of the compression flange; he also found that the web contribution to bending is negligible. Chan et al. [27] studied bending behavior for girders with different web corrugation and found that an increase of corrugation radius increases the bending capacity. Some other studies include Abbas et al. [28], Wang and Young [29], where an effect of web perforation on bending was investigated. Jáger et al. [30] performed experimental studies on flange buckling. Lateral torsion-flexure buckling was further studied by Sayed-Ahmed [31] and bending-shear interaction for girders with trapezoidally corrugated web beams was studied by Kövesdi et al. [32]. In recent years, steel arches with circular corrugated web were investigated experimentally and numerically by Guo et al. [2, 4] for inplane strength and failure mechanism prediction. Quite an important problem for the corrugated-web I beams concerns boundary conditions on their web-to flange connection. They were studied by Hassanein et al. [33] and found to be nearly fixed. In this study, all the fillet welds are introduced to adequately represent boundary conditions on this joint.

Computational fire simulation problems and their solutions are quite well documented in engineering literature, specifically for steel structures. Steel frames in fire conditions were investigated by Najjar and Burgess [34], Liew et al. [35] and Landesmann et al. [36], while complete steel frame buildings by Wald et al. [37]. The behavior of steel bridges under fire was studied by Aziz et al. [38] and Kodur et al. [39] and steel beams in fire with open and closed connections were investigated by Laím, and Rodrigues [40]. The endplate connections in elevated temperatures were investigated by Qiang [41] and columns under localized fire were tested by Zhang et al. [42]. Experiments on sinusoidal-web beams subjected to high temperatures can be found in [43]. A study of residual stresses in welds after fire exposure was performed by Wang et al. [44] who also studied axially restrained trapezoidal web I girders $[45,46]$. Some other papers are focused on shear buckling of corrugated-web beams under fire [47,48] or propose an analytical model of heat conduction on web-to-flange connection [49]. None of these cover the global buckling resistance or eigenfrequencies during fire, which are investigated here.

The main topic of this study is a nonlinear analysis of a high strength steel corrugated-web plate girder under transient fire temperature conditions. It takes into account efficiency and accuracy of three various transient coupled thermo-elastic analyses. All the resulting stress distributions, deformation modes and their time variations, critical loads and eigenfrequencies as well as failure times are compared for three different material models. Nonlinearities include material, geometrical and contact phenomena as well as the temperature-dependent constitutive relations of the high strength steel; they partially result from steady state and transient experimental tests or from the additional designing rules included in Eurocodes. A fire scenario includes an application of the normative fire gas temperature curve on the bottom flange of the entire girder 
for a period of 180 minutes. It is analyzed numerically using the coupled thermo-elastic Finite Element Method that accounts for heat conductivity, radiation and convection. The FEM model consists of a combination of 3D hexahedral and tetrahedral solid finite elements. Such an approach allows drawing conclusions on the behavior of such girder during fire with a specific fire scenario and allows a comparison of behavior of different numerical models having close results in the steady state. This study is aimed at realistic fire more than at a study in an elevated temperature, where the heat is evenly distributed in an entire girder. This is because such perfect heating conditions are almost never observed in an event of fire. It should be finally outlined that the presented corrugated girder model mesh used here will find its direct application in further reliability analysis according to both First and Second Order Reliability Methods [40] implemented according to the Stochastic perturbation-based Finite Element Method. In the future, special attention should be paid to analytical determination of the shear center curve throughout the length of such a cross-section as well as derivation of the critical moment to verify stability of such a girder under combined twisting and bending.

\section{Finite Element Method model of the girder}

The 40,0 meters long and simply supported corrugated I girder, $2500 \mathrm{~mm}$ high, $1400 \mathrm{~mm}$ wide, with flange thickness of $100 \mathrm{~mm}$ and web thickness of $56 \mathrm{~mm}$ is considered here. It has the following corrugation function of the web:

$$
s\left(x_{2}\right)=60 \sin \left(\frac{\pi x_{2}}{20}\right) \quad[\mathrm{mm}]
$$

It is made of the high strength steel S460 and is subjected to the uniformly distributed load of $q=150 \mathrm{~N} / \mathrm{mm}$ applied symmetrically on its upper flange; it is accompanied by the girder dead load.

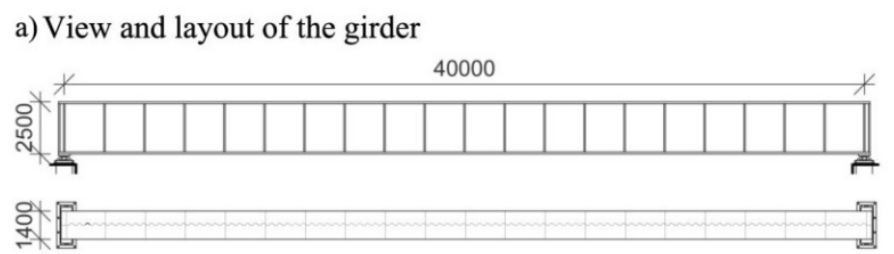

c) Section details

b) Corrugated web pattern
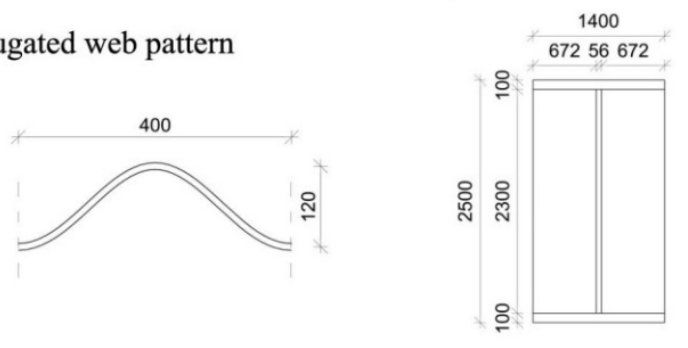

Fig.1. Sketch of the girder [mm].

Spatial distribution of both-sided rectangular ribs equals $2000 \mathrm{~mm}$, their thickness equals $56 \mathrm{~mm}$ and the fillet weld is $10 \mathrm{~mm}$ thick. The last two ribs distance close to the support equals $280 \mathrm{~mm}$. A diameter of the roller on the simple support has been designed as $240 \mathrm{~mm}$. A sketch of this girder is available in Fig.1 together with its most essential dimensions; Fig.1a shows the view and layout of the girder, Fig.1b the corrugated web pattern and Fig.1c the dimensioning and details of the girder section. A discretization of the girder is made with the use of the FEM program ABAQUS Standard by an application of about 570000 
linear hexahedral C3D8R finite elements and 150000 quadratic tetrahedral C3D10 elements, 93 independent parts and 563 instances tied by 1300 connections.
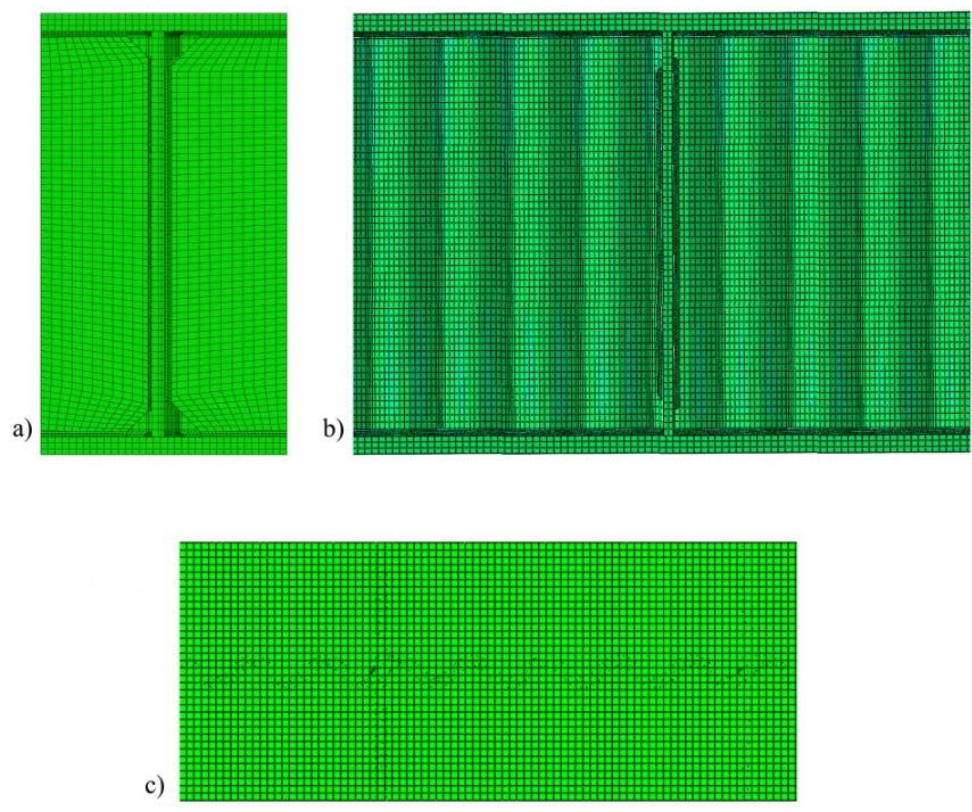

Fig.2. ABAQUS discretization of the girder.
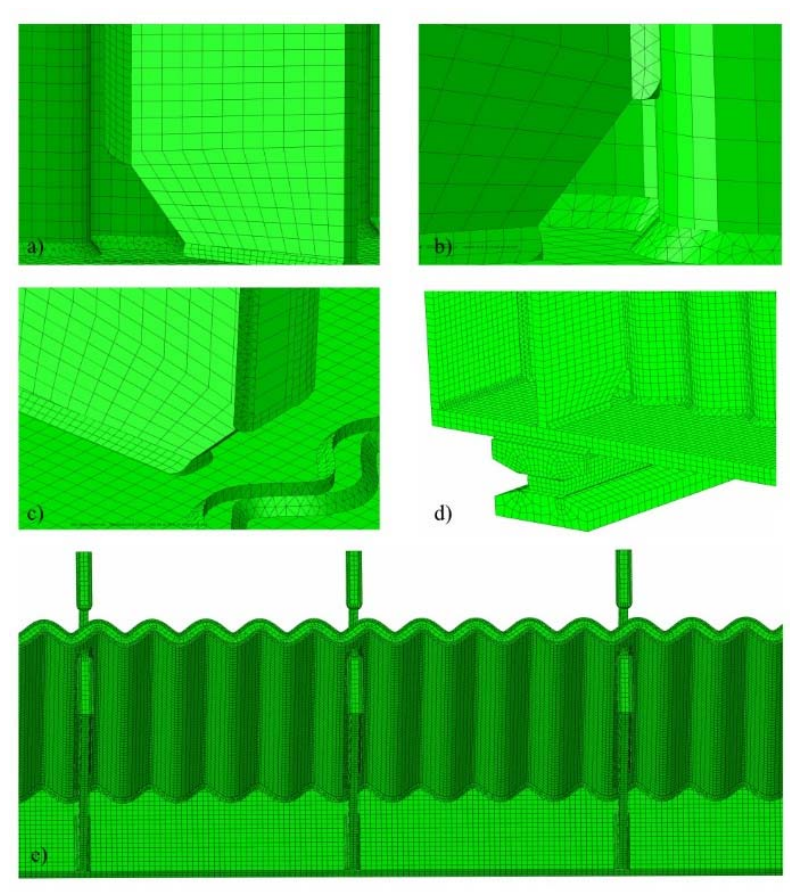

Fig.3. Details of the girder model.

The tetrahedral elements are principally used in the welds due to their complex geometry while hexahedra - to mesh the other parts of this structure. All these details including the web, both flanges, vertical ribs, welds and supports are contained in Figs 2-3. Figure 2a presents the section of the girder, 
Fig.2b, a view on the right side of this girder and Fig.2c the view of the flange together with a discretization. Figures $3 \mathrm{a}$ and $3 \mathrm{~b}$ present the vertical ribs, Fig.3c, the web-to-flange and rib-to-web welding, Fig.3d the support and Fig.3e the corrugated web. This model includes a connection of the girder with the roller in the form of a surface contact with a hard normal contact definition, Lagrange tangential behavior and friction coefficient equal $\mu=0.15$.

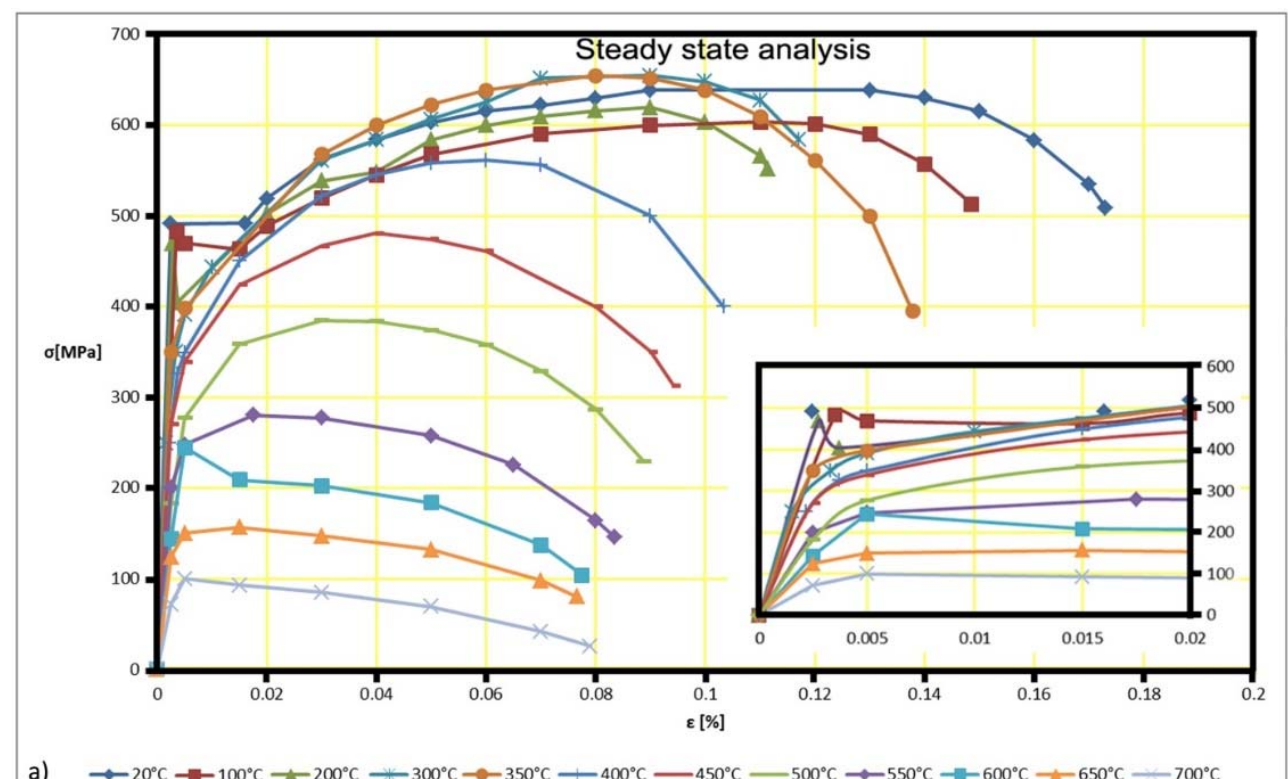

a) $\rightarrow 20^{\circ} \mathrm{C} \rightarrow-100^{\circ} \mathrm{C}=200^{\circ} \mathrm{C}-300^{\circ} \mathrm{C} \rightarrow 350^{\circ} \mathrm{C}+400^{\circ} \mathrm{C}-450^{\circ} \mathrm{C}-500^{\circ} \mathrm{C} \rightarrow 550^{\circ} \mathrm{C} \rightarrow-600^{\circ} \mathrm{C} \rightarrow 650^{\circ} \mathrm{C} \longrightarrow 700^{\circ} \mathrm{C}$

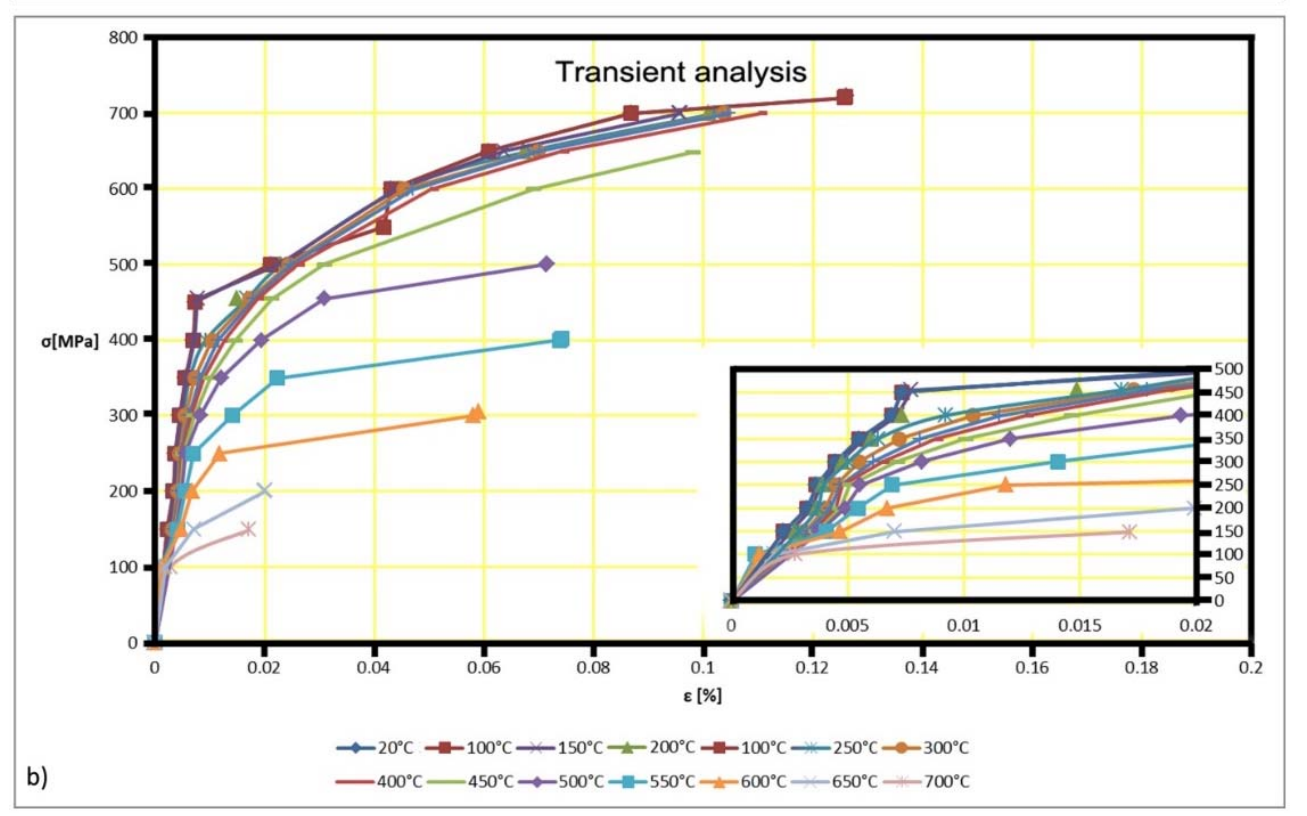

Fig.4. Experimental constitutive relations of steel S460 in (a) steady state and (b) transient state.

Experimental constitutive models are applied in the computational study and are schematically presented in Fig.4. They are coming from experimental tests contained in [41] (materials 2 and 3) or from the Eurocode (material 1). These relations have been converted into true stress, true strain and plastic strain prior to their application in the ABAQUS inputs. Figure 4 a represents stress-strain relation for the steady state tests, where the specimen is heated up to a specified temperature and then loaded in tension until failure 
while maintaining the same temperature. Steel under such conditions has a very ductile behavior with a long hardening and softening phase before failure. For temperatures close to ambient, the strain at failure is 0.18 and it is reduced together with an increase of temperature to 0.08 for $700^{\circ} \mathrm{C}$. The increase in temperature also reduces the maximum stress in this material from $640 \mathrm{MPa}$ till $100 \mathrm{MPa}$ for $700^{\circ} \mathrm{C}$. Fig $4 \mathrm{~b}$ represents the constitutive relation for the transient state test, where the specimen is kept under a constant tensile load and the temperature is increased until failure. Failure for the transient state happens at lower strain intensities than for the steady state $\left(0.013\right.$ at ambient temperature and 0.02 for $\left.700^{\circ} \mathrm{C}\right)$ and linear elastic behavior is lost early during the uploading process even for moderate temperatures. The stress allowed at higher temperatures is, however, higher than for the steady state. This behavior is much closer to the fire exposition conditions imposed in the numerical study. First, because the external load is kept constant for the entire time span and secondly, because the temperature exclusively increases in the proposed fire scenario. The fire curve in the transient state for $20^{\circ} \mathrm{C}$ was unavailable in the experimental study. This curve was assumed after the measurement in the transient state for $100^{\circ} \mathrm{C}$. This was regarded as a better replacement than applying the result from the steady state for $20 \mathrm{C}$; in this way a separation of the steady and transient state behavior was ensured; for more details on the experimental tests, please refer to [41]. An approximation between the data points (represented in Fig.4a and 4b) and discrete temperatures is linear in the entire spectrum of the study and such a linearization is frequently recommended by the Eurocode statements.

\section{Computer simulation of a fire below the girder}

The FEM simulation of a fire is realized with ABAQUS using the sequentially-coupled temperaturedisplacement FEM study with the normative outer fire curve affecting the bottom surface of the girder lower flange and it varies in time according to the following formula (Fig.5, red surface):

$$
\theta_{g}=660\left(1-0.687 e^{-0.32 t}-0.313 e^{-3.8 t}\right)+20
$$

where $\theta_{g}$ is a gas temperature close to the bottom surface, whose maximum magnitude equals $680^{\circ} \mathrm{C}$; time variations of this fire curve are depicted in Fig. 5 by a red line. Such fire conditions may serve for a worst case fire scenario in (1) a single span of a bridge subjected to fire underneath the girder or (2) segmental ceilings for a fire underneath this ceiling.

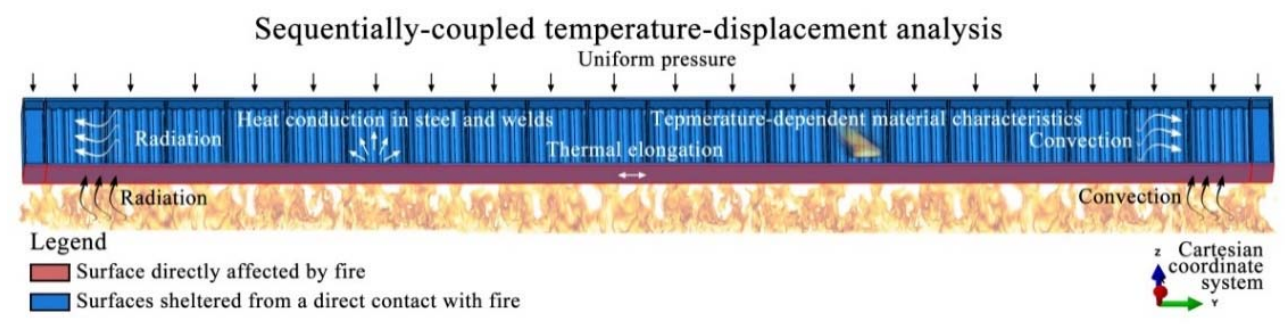

Fig.5. A general scheme of the sequentially-coupled temperature-displacement analysis.

In such applications this scenario is much worse than the partial heat exposure observed usually in the early stages of fire. It substantially increases the overall deflection (important for the SLS of the girder) and the normal longitudinal stresses in the girder mid-span $\sigma_{22}$, which usually serve for a limit case for its ULS. It also causes uneven longitudinal elongation of the girder, where the lower flange is much more elongated than the higher one. When this elongation is restrained during fire, additional stress concentrations are placed on the web and bottom flange of the girder. An exemplary ceiling structure following the proposed fire scenario is presented in Fig.6. It is considered a-priori that fire gases will not penetrate the brick-to girder connection and that convection is possible from the outer surfaces of the web, ribs and an upper flange. This 
results in a strong gradient of temperature on the web and a very limited increase of temperature on the top of the girder. It may be a little higher in a real structure because of the neighboring elements getting heated and a limited heat outflow from the web. This does not affect much the mechanical behavior of the girder, where main forces sustaining the load are located on the higher and lower flanges.

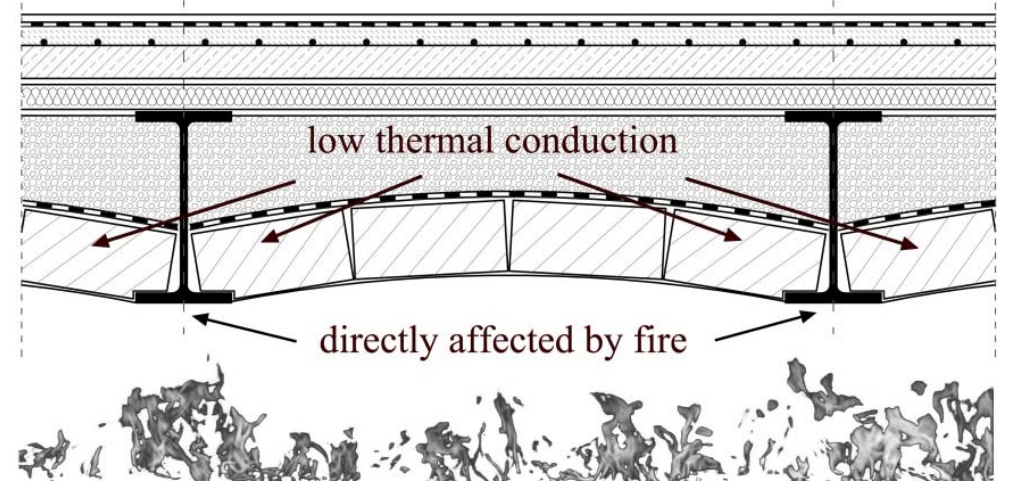

Fig.6. Cross-section of the exemplary ceiling structure subjected to fire.

Table 1. Temperature fluctuations of the structural steel material properties.

\begin{tabular}{|c|c|c|c|c|c|c|}
\hline $\begin{array}{l}\mathrm{T} \\
{\left[{ }^{\circ} \mathrm{C}\right]}\end{array}$ & $\begin{array}{l}k(T) \\
{[W / m K]}\end{array}$ & $\begin{array}{l}c(T) \\
{[J / k g K]}\end{array}$ & \multicolumn{3}{|c|}{$\begin{array}{l}E(T) \\
{[\mathrm{MPa}]}\end{array}$} & $\begin{array}{l}f_{y} \\
{[\mathrm{MPa}]}\end{array}$ \\
\hline \multicolumn{3}{|c|}{ All models } & $\begin{array}{c}I^{\text {st }} \\
\text { material }\end{array}$ & $\begin{array}{c}2^{\text {nd }} \\
\text { material [41] }\end{array}$ & $\begin{array}{c}3^{\text {rd }} \\
\text { material }[41]\end{array}$ & $\begin{array}{c}3^{\text {rd }} \\
\text { material [41] }\end{array}$ \\
\hline 20 & 53.3 & 440 & 210000 & 202800 & 201900 & 723 \\
\hline 100 & 50.7 & 488 & 210000 & 198900 & 199700 & 722 \\
\hline 200 & 47.3 & 530 & 189000 & 177900 & 175680 & 700 \\
\hline 300 & 44.0 & 565 & 168000 & 161300 & 159900 & 700 \\
\hline 400 & 40.7 & 606 & 147000 & 135100 & 134482 & 700 \\
\hline 500 & 37.4 & 667 & 126000 & 102800 & 97300 & 501 \\
\hline 600 & 34.0 & 760 & 65100 & 58700 & 54900 & 402 \\
\hline 700 & 30.7 & 1008 & 27300 & 30900 & 26700 & 149 \\
\hline \multicolumn{6}{|c|}{$\rho=7720 \frac{\mathrm{kg}}{\mathrm{m}^{3}}, \quad \alpha_{v}=34 \times 10^{(-6)}$} & \\
\hline
\end{tabular}

Temperature-dependent material properties in three different coupled FEM models of the girder are contained in Tab.1 and Fig.4. They include thermal conductivity, specific heat, Young modulus and yield stress; the last parameter has been defined for the third model only. All of the models are strongly temperature-dependent and, additionally, exhibit large deformations in the FEM analysis. Interpolation of Young modulus and yield stress in between the temperature points is linear. Similarly to the steady-state analysis results, the differences in these models follow from the support geometry meshing and from the constitutive relation type - linear elastic temperature-independent material characteristics, while the next two include strongly non-linear constitutive relations adopted after some experimentation. These physical nonlinearities come from the steady state analysis $\left(2^{\text {nd }}\right.$ model $)$ and, independently, from transient thermo- 
elastic problem for systematically increasing temperature ( $3^{\text {rd }}$ model); they follow the experimental results from [41] (Fig.4a and Fig.4b). The $1^{\text {st }}$ model exhibits reversible linear-elastic stress-strain relation, the $2^{\text {nd }}$ model relation follows curves from Fig.4a and the $3^{\text {rd }}$ model follows constitutive relation from Fig.4b. Interpolation of the stress-strain relation for an increasing temperature is linear between the temperature curves. Such models are adopted because (1) one could compare the effect of different nonlinear constitutive relations with the same geometry (the $2^{\text {nd }}$ model with the $3^{\text {rd }}$ model) and also compare (2) a simplified model with not exact supports and linear constitutive law with more detailed models (the $1^{\text {st }}$ model with the $2^{\text {nd }}$ or $3^{\text {rd }}$ models). The external vertical load is assumed to be constant throughout the coupled analysis. The Newton technique with non-symmetric system matrices is employed here to carry out an incremental analysis - a constant time increment of 60 seconds is applied in the first model (180 increments with extreme temperature increase equal to $25^{\circ} \mathrm{C}$ ) and an automatic increment of maximum 60 secs and extreme temperature increase equal to $20.5^{\circ} \mathrm{C}$ is used in the second model and the same automatic incrementing and extreme temperature increase equal to $15.3^{\circ} \mathrm{C}$ is used in the third model. The extreme temperature increase in these last two models is out of control for the user - only the maximum allowable temperature increase could be preset, which for both models was defined as $25^{\circ} \mathrm{C}$. Please note that setting of exactly the same temperature increments for the nonlinear models is practically unfeasible here.

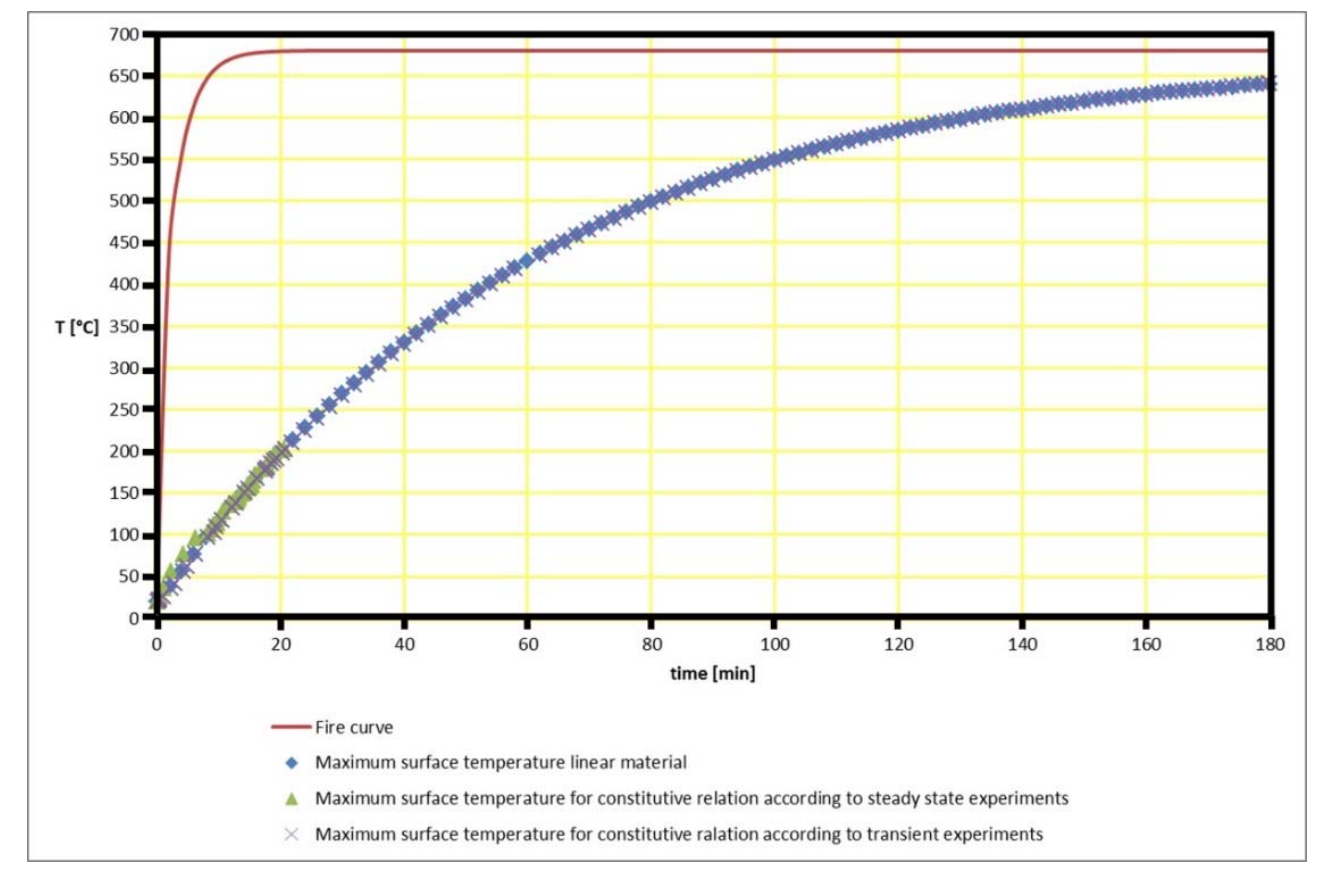

Fig.7. External and ultimate temperature versus time from fire ignition.

One cannot predict the optimum constant time increment, as in the case of the $1^{\text {st }}$ model, because their stiffness matrices are highly dependent on temperature and by this - on time increment of the analysis. Each consequent time increment must be set basing on the accuracy and convergence of the solution for the current step. It is demonstrated here that the $2^{\text {nd }}$ model loses convergence after 20 minutes of numerical analysis with only $200^{\circ} \mathrm{C}$ on the bottom flange, whereas the third one is able to be heated up to $640^{\circ} \mathrm{C}$, where the simulation is very close to the steady state (Figs 7-9). This is due to the ability of the $3^{\text {rd }}$ model to sustain a remarkable stress redistribution at the relatively high strain rates available principally due to the lack of stress softening or, alternatively, crack initiation and propagation rule defined for the given material. The results in Figs 7-9 show in turn extreme temperature, the reduced stress and also extreme vertical displacement curves in relation to the time from fire ignition. Firstly, they indicate a convergence to the steady state conditions after 180 minutes of fire exposure. 


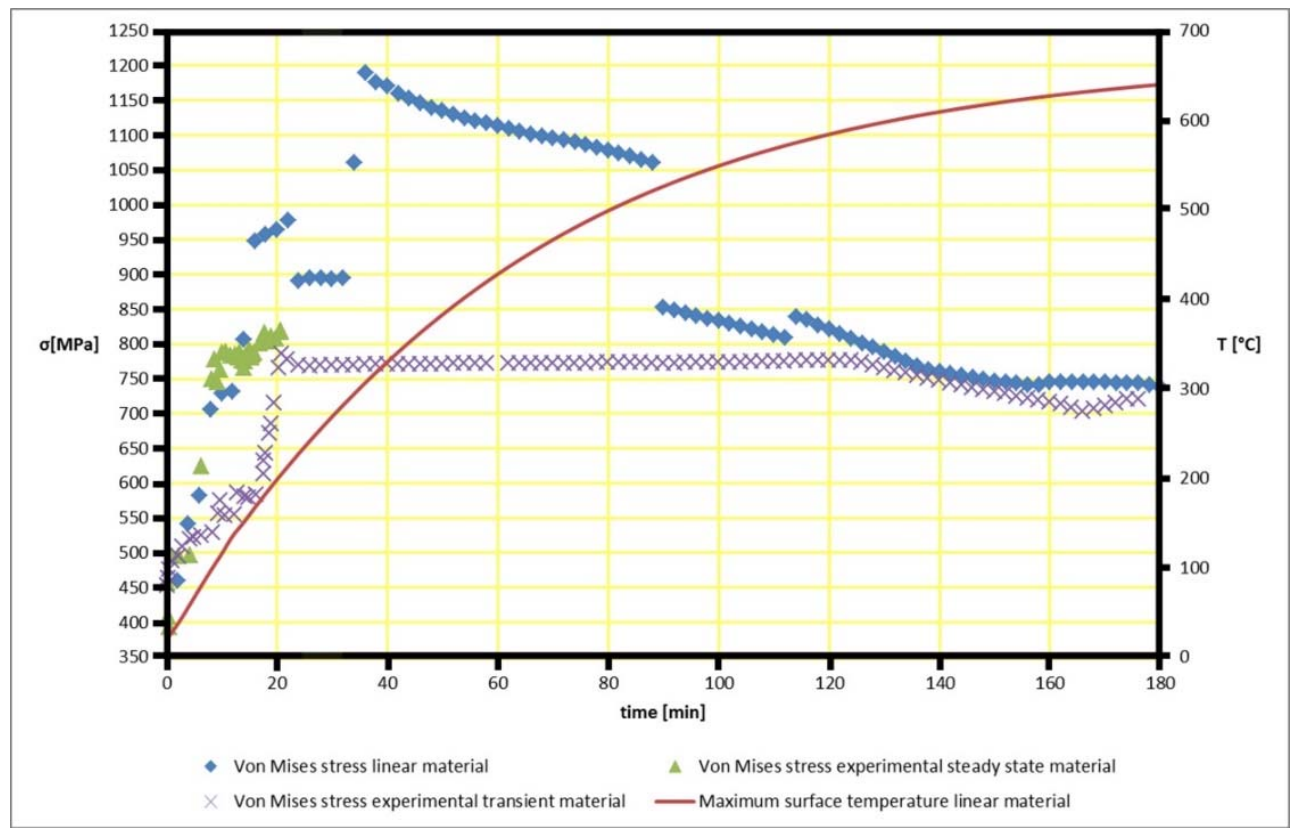

Fig.8. External temperature and ultimate von Mises stress vs. time from the fire ignition.

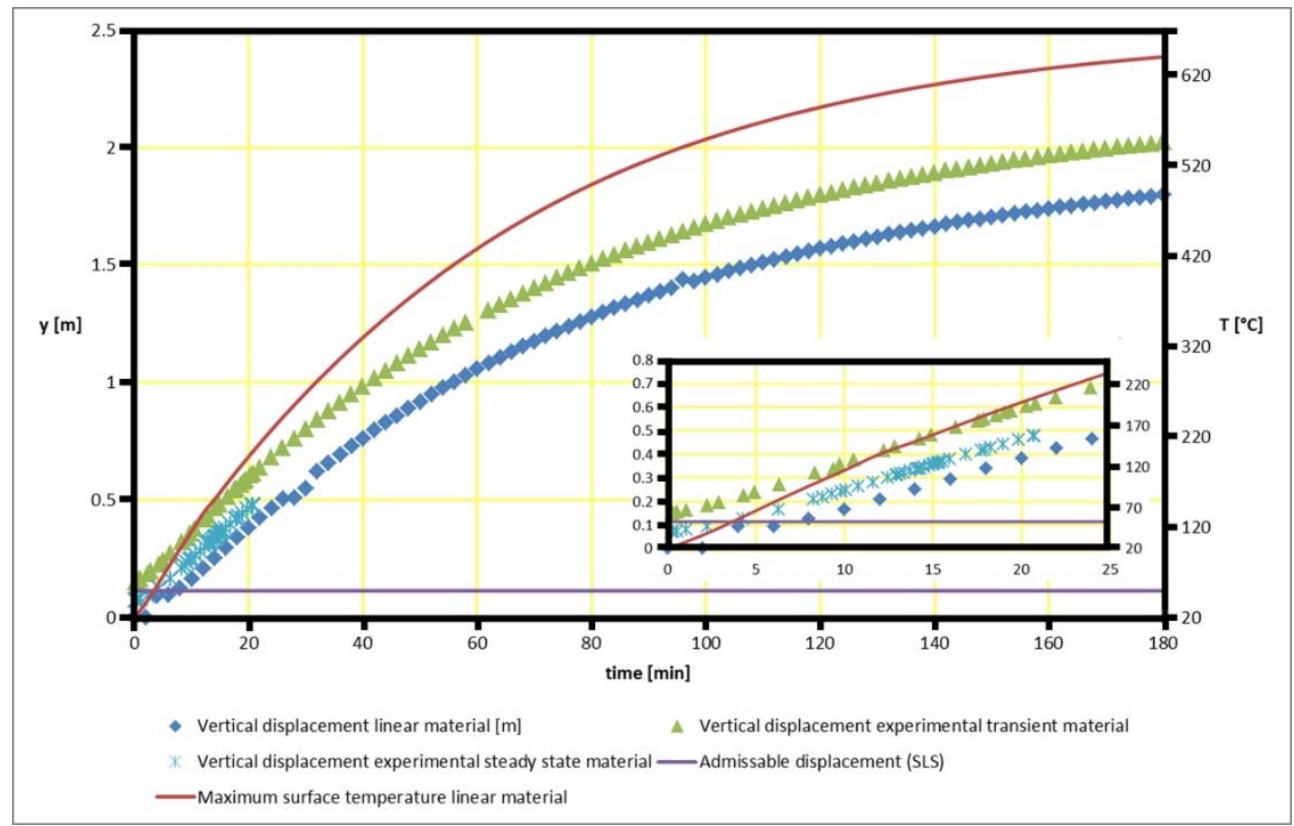

Fig.9. External temperature and ultimate displacement vs. time from the fire ignition.

As it is documented in Fig.8, a resistance of the second model is equivalent to about 21 minutes of such an exposure. The extreme girder temperature shown on Fig.7 is very close for all the three models, it always increases together with an increase of time of fire and reaches $613^{\circ} \mathrm{C}$ after 180 minutes. The reduced stress presented in Fig.8. is entirely different for each model. The $1^{\text {st }}$ model allows very large stress concentrations up to $1200 \mathrm{MPa}$, which are strongly reduced for the next two concurrent models to around $800 \mathrm{MPa}$ because of their nonlinear constitutive models. This model also allows very high jumps of stresses in the subsequent time increments of up to $100 \mathrm{MPa}$, which are not existent for the other models. The reason for this behavior is a combined effect of three major factors, i.e. (1) simplified supports geometry, (2) simple 
linear constitutive relation (allowing also stresses over the plastic limit) and (3) a fixed time increment applied in the transient analysis; quite interestingly, this model returns very high stress concentrations already in the ambient temperature.

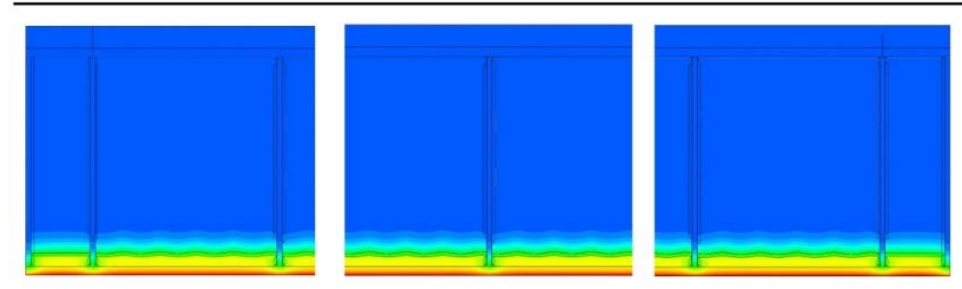

a) model after $20 \mathrm{~min} 43 \mathrm{sec}$ of the fire exposition
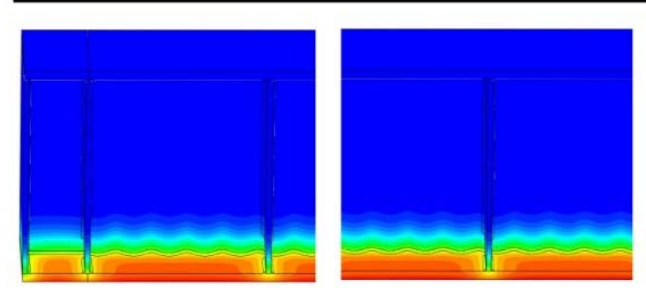

b) model after $60 \mathrm{~min}$ of the fire exposition
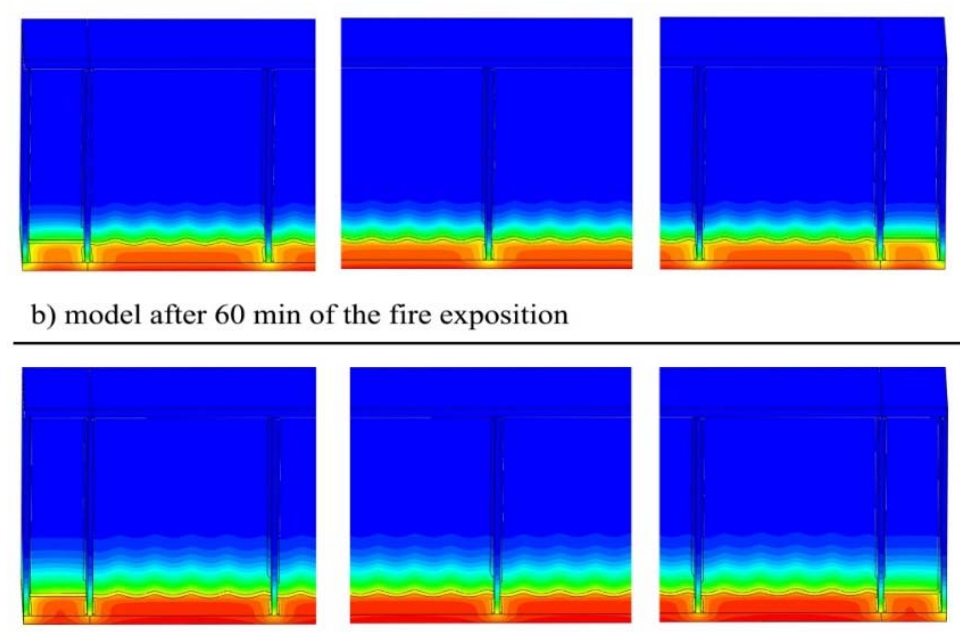

c) model after $120 \mathrm{~min}$ of the fire exposition
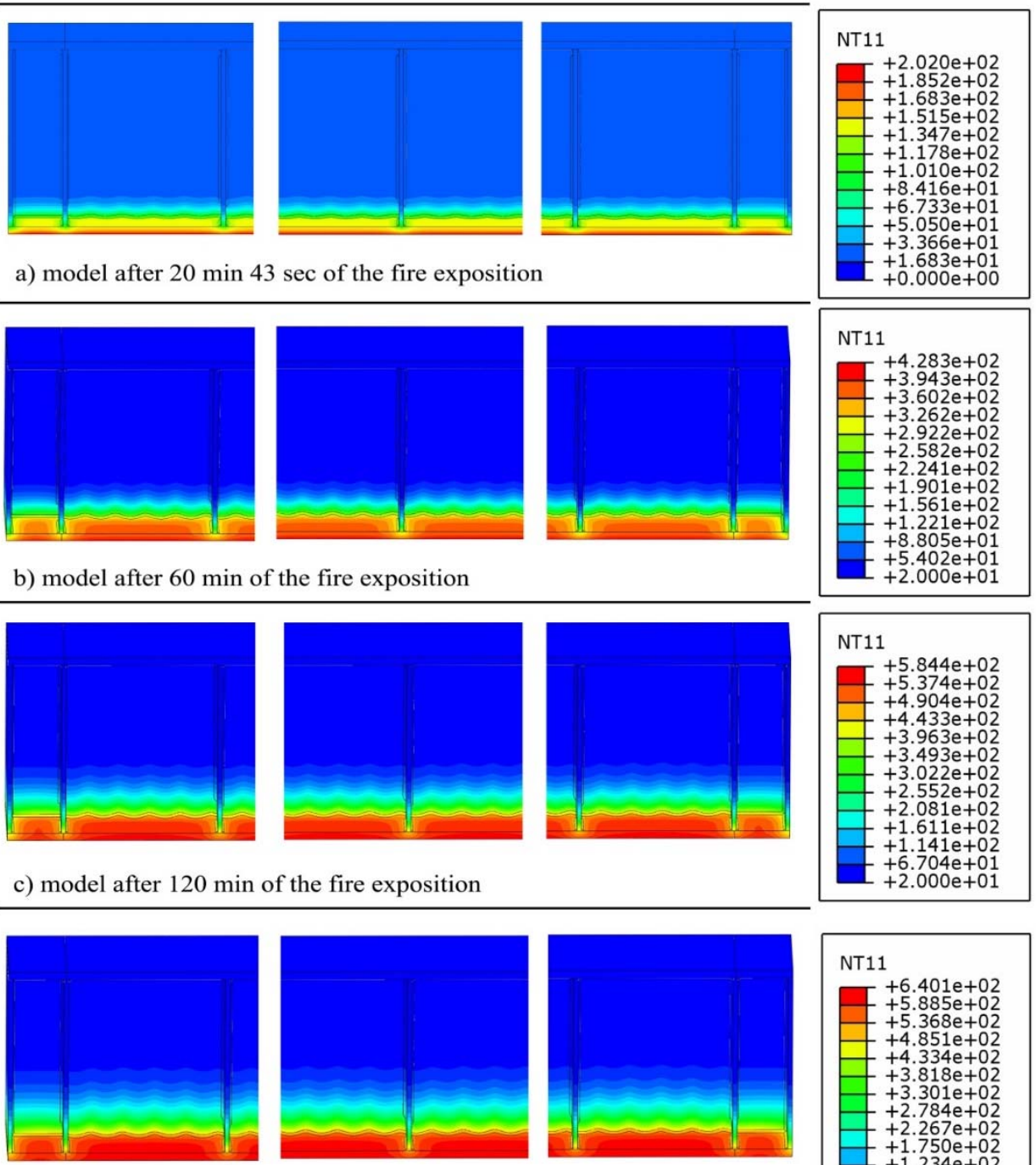

d) model after $1800 \mathrm{~min}$ of the fire exposition
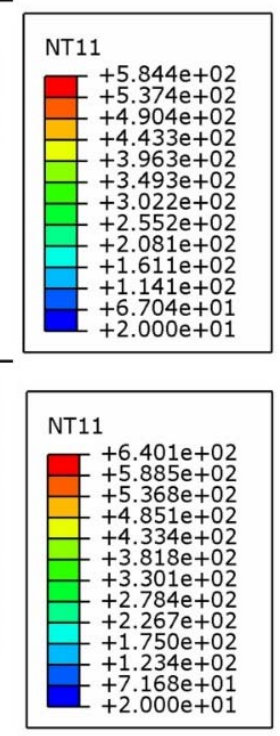

Fig.10. Distribution of the girder temperatures during fire simulation after (a) 20 minutes (b) 60 minutes (c) 120 minutes and (d) 180 minutes of the fire exposition.

The stress fluctuation for the two remaining models also differ from each other - the $2^{\text {nd }}$ one reaches its extreme stress and fails thereafter (for a little bit higher bottom flange temperature), while the third one redistributes the stress deeper into the web (Figs 8 and 12); this further ensures the inability of the $2^{\text {nd }}$ model to redistribute the stresses. Interestingly, the $3^{\text {rd }}$ model shows the smallest values of the stress up to 20 minutes of the fire exposition, which may be the effect of some kind of stress redistribution also for the girder already entering plastic strain (which for transient tests starts already at 150-300 $\mathrm{MPa}$ ). Finally, at around 120 minutes of fire exposition a decrease of the maximum reduced stress in models 1 and 3 is observed. It clearly results from a high temperature in the bottom side of the girder, which reaches up to $1 / 5$ of its height, and also from the temperature softening of the properties of steel (refer to the stress curves for 
increasing temperatures in Fig.10). The ultimate stress position is not constant along the transient analysis especially in the nonlinear models. This further exemplifies (at least partial) stress redistribution in this girder propagating together with an increase in temperature gradient existent in the girder and, also, an increase in time of fire exposure. From Fig. 8 it is additionally seen that the maximum stresses in the $1^{\text {st }}$ model reach $1200 \mathrm{MPa}$ after 39 minutes of fire exposition, for the $2^{\text {nd }}$ model $-823 \mathrm{MPa}$ (at its failure after 20 minutes) and for the third model $-786 \mathrm{MPa}$, also around 20 minutes of fire exposition. For the $1^{\text {st }}$ model a strong stress softening is observed just after reaching the ultimate stress, while for the $3^{\text {rd }}$ model some small stress softening is observed after 20 minutes of fire exposition, than a constant maximum stress is kept up to 128 minutes of fire exposition and some additional stress softening takes place thereafter. Interestingly, after around 128 minutes of fire exposition the two models have almost unique maximum stresses.
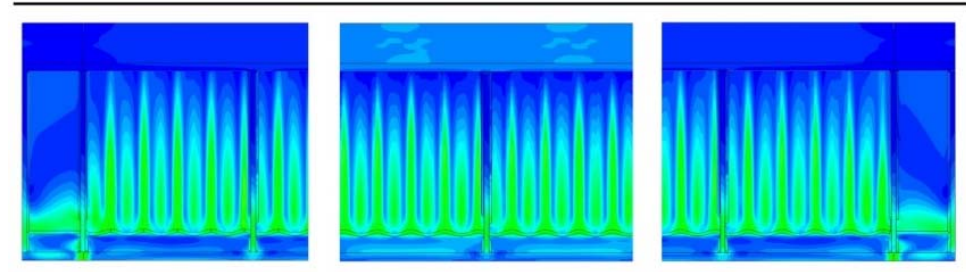

a) $1^{\text {st }}$ model at $21^{\text {st }}$ min. after fire ignition
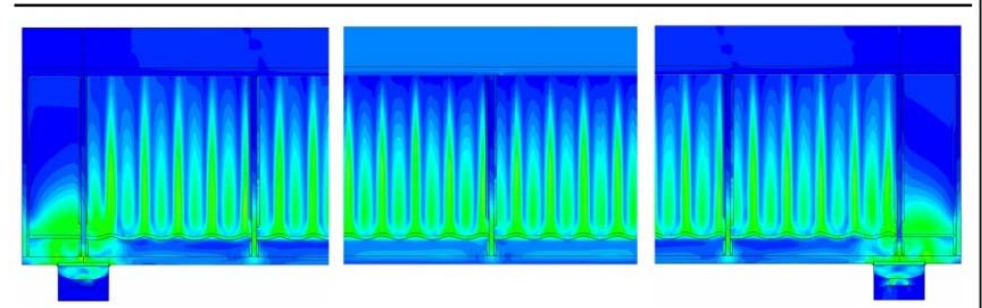

b) $2^{\text {nd }}$ model at $20^{\text {th }}$ min. $43^{\text {th }}$ sec. after fire ignition
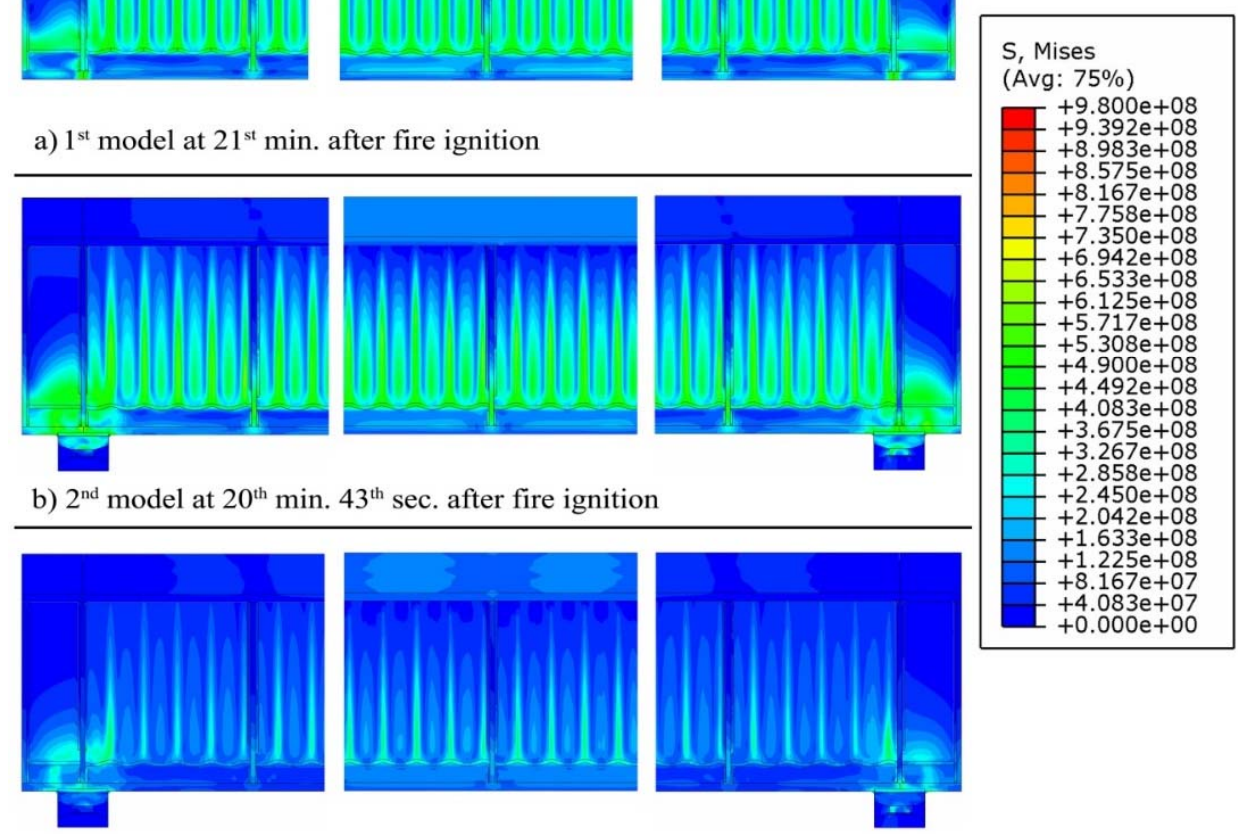

c) $3^{\text {rd }}$ model at $20^{\text {th }}$ min. $48^{\text {th }}$ sec. after fire ignition

Fig.11. Reduced stress $\sigma_{\text {red }}$ during fire simulation at failure of the $1^{\text {st }}$ model in (a) the $1^{\text {st }}$, (b) the $2^{\text {nd }}$ and (c) the $3^{\text {rd }}$ model.

The stiffness of the girder reflected here by its mid-span vertical deflection dramatically decreases in time of the fire (see Fig.9). Deflection starts from the initial $7.8 \mathrm{~cm}$ and it reaches up to $200 \mathrm{~cm}$ in the $3^{\text {rd }}$ model and $170 \mathrm{~cm}$ in the $1^{\text {st }}$ model. This, of course, is a direct effect of a reduction of steel properties in higher temperatures. The $1^{\text {st }}$ model appears to be the stiffest one because of no reduction in the Young modulus during transient analysis of fire and also because of a lack of the strain hardening / softening in the material definition. The softest is the $3^{\text {rd }}$ model with material definition very close to realistic conditions of the fire accident; it demonstrates plastic deformation even at $150 \mathrm{MPa}$. At this stress level in steady-state conditions this material would still be in linear elastic reversible regime (Fig.4). A temperature inflow into the girder non-linearly increases together with the fire exposition time and, similarly to maximum temperature, stabilizes during this process, which results from heat radiation and convection on the sidewalls of the web. This can be observed in Figs 7 and 10, which additionally show a very high temperature of the 
bottom flange that decreases rapidly in the vertical direction, especially inside the web. This is because the external air temperature is kept at $20^{\circ} \mathrm{C}$ throughout the entire simulation except the bottom flange, which is a considerable simplification of the problem. Such an assumption is well justified by the coverage of the upper part of the girder with the secondary steel elements, bridge deck and its reinforced concrete surface and therefore is not directly affected by the fire flames.

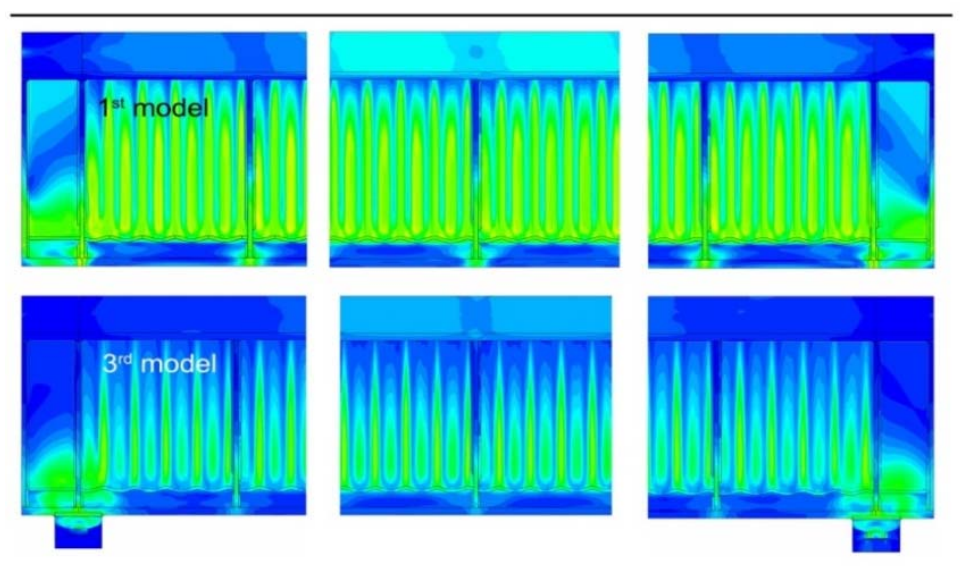

a) model after $60 \mathrm{~min}$. of the fire exposition
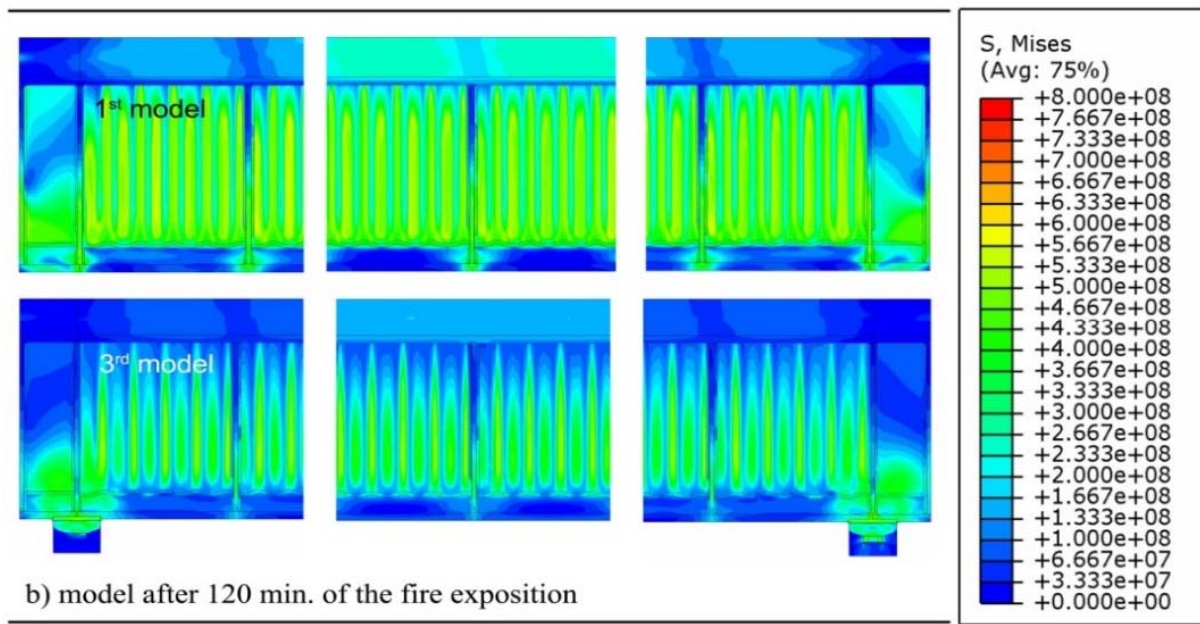

b) model after $120 \mathrm{~min}$. of the fire exposition
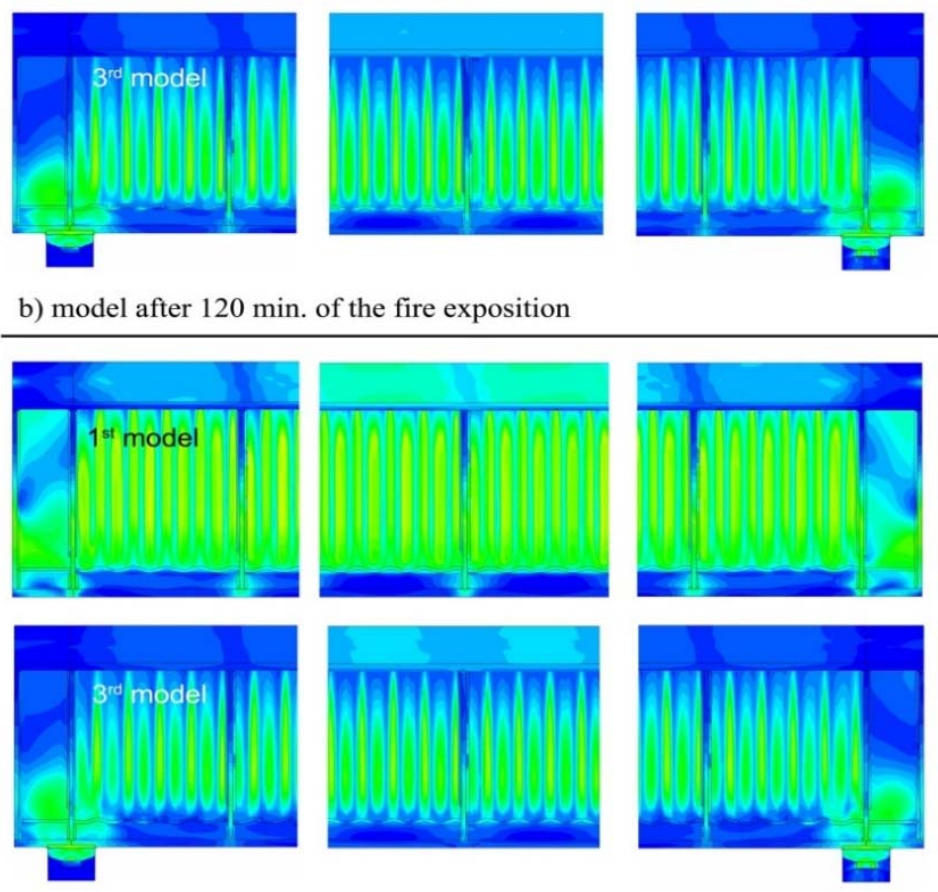

c) model after $180 \mathrm{~min}$. of the fire exposition

Fig.12. Reduced stress $\sigma_{\text {red }}$ after (a) 60 minutes (b) 120 minutes and (c) 180 minutes of the fire exposition. 
The extreme reduced stress time fluctuations during the fire event do not provide full information on the stress state in the girder. It is reported here in Fig. 11 in the form of stress maps for the failure time of the first model, where Fig.11a shows the results for the $1^{\text {st }}$ model, Fig. $11(\mathrm{~b})$ for the $2^{\text {nd }}$ model and Fig.11c for the third model. Such stress maps are also shown in Fig.12 for the $1^{\text {st }}$ and the $3^{\text {rd }}$ models after 60 (Fig.12a), 120 (Fig.12b) and 180 minutes (Fig.12c) after the fire ignition. These maps are very different from these computed for the steady state model in $20^{\circ} \mathrm{C}$ mainly because of large, irreversible partially plastic deformations and significant temperature-dependent reduction of structural steel properties. The differences between the models are already remarkable even in the first minutes of fire exposition and become significant for the failure time in the second model (cf. Fig.11).

This approximate time results from the incremental nature of the strain-dependent analysis, which is performed here with time increment modified during the transient analysis. Although the general stress distribution is similar in different computer models, its extreme magnitude does not remain the same. The major differences appear in the bottom flange at the mid-span, where the stress concentrations are distributed either in an oval manner or do not exist at all; they are also remarkable on the upper flange at the same location, where some periodic concentrations of these stresses are localized. Quite opposite to the steady state results, the web in the transient state exhibits the stresses definitely larger than the flanges after about $21^{\text {st }}$ minute of this simulation and this disproportion further increases together with the simulation time (Fig.12). Interestingly, the $2^{\text {nd }}$ model at failure does not reach the limit stresses so that this failure may occur as the result of strain softening. Longer fire exposition times (higher temperatures) show a redistribution of the stresses from the lower flange into the web (Fig.12). The web plays a major role in the bending capacity and the extreme reduced stresses are localized on it also. This happens for both models being compared (and also for the $2^{\text {nd }}$ one before the failure), but it is more apparent for the $3^{\text {rd }}$ (bottom) one, where these concentrations are initiated in the lower web-flange welds and vanish close to the upper flange with some additional peak close to the middle of the flange. Such a behavior is observed for both shear and bending zones, which results in the web having the highest stress in the girder in this particular fire scenario. This behaviour principally results from a combination of all periodic fluctuations of normal and tangent stresses, which partially results from thermal expansion of the girder itself and, additionally, from a redistribution of the stresses into a corrugated web.

Table 2. Comparison of the eigenfrequencies and critical loads for the beam at the fire ignition and after $180 \mathrm{~min}$ of fire.

\begin{tabular}{|c|c|c|c|c|c|c|c|c|c|}
\hline \multicolumn{10}{|c|}{ Eigenfrequencies and buckling loads at the beginning of and after $180 \mathrm{~min}$ of fire } \\
\hline \multirow{7}{*}{ 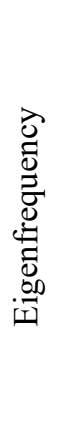 } & \multirow{2}{*}{$\begin{array}{l}\text { Mode } \\
\text { No. }\end{array}$} & \multirow{2}{*}{$t=0 \mathrm{~min}$} & \multicolumn{2}{|c|}{$t=180 \mathrm{~min}$} & \multirow{7}{*}{ 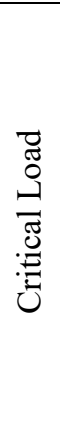 } & \multirow{2}{*}{ Mode No. } & \multirow{2}{*}{$t=0 \mathrm{~min}$} & \multicolumn{2}{|c|}{$t=180 \mathrm{~min}$} \\
\hline & & & $1^{\text {st }}$ model & $3^{\text {rd }}$ model & & & & $1^{\text {st }}$ model & $3^{\text {rd }}$ model \\
\hline & 1 & 1.7287 & 1.2847 & 1.7535 & & \multirow{2}{*}{1} & \multirow{2}{*}{8.4153} & \multirow{2}{*}{5.552} & \multirow{2}{*}{7.9796} \\
\hline & 2 & 3.1569 & 3.0823 & 3.3812 & & & & & \\
\hline & 3 & 4.3927 & 3.1244 & 3.4361 & & \multirow{2}{*}{2} & \multirow{2}{*}{18.295} & \multirow{2}{*}{15.869} & \multirow{2}{*}{19.831} \\
\hline & 4 & 6.3105 & 4.4272 & 5.3874 & & & & & \\
\hline & 5 & 8.9400 & 7.8700 & 8.0960 & & 3 & 40.201 & & \\
\hline
\end{tabular}

The critical loads and eigenfrequencies are also sensitive to the fire exposition. Table 2 reports these values before and after 180 minutes of the fire exposition. It clearly indicates significantly lower first critical load -8.42 for the steady state vs. 5.55 for the $1^{\text {st }}$ and 7.97 for the $3^{\text {rd }}$ model in the transient state. The differences in eigenfrequencies before and after 180 minutes of fire exposition indicate a significant decrease in the $3^{\text {rd }}$ and $4^{\text {th }}$ resonance frequency after the fire exposure $-4.39 \mathrm{~Hz}$ vs. $3.12 \mathrm{~Hz} / 3.43 \mathrm{~Hz}$ and $6.31 \mathrm{~Hz}$ vs. $4.42 \mathrm{~Hz} / 5.38 \mathrm{~Hz}$. The $1^{\text {st }}$ and the $2^{\text {nd }}$ eigenfrequencies are a little less affected. Only the $1^{\text {st }}$ model reports a significant reduction in the $1^{\text {st }}$ eigenfrequency after 180 minutes of fire exposition $-1.73 \mathrm{~Hz}$ vs. $1.28 \mathrm{~Hz}$. 
This model, however, is less adequate than the $3^{\text {rd }}$ one. Generally, one may notice that the fire exposition of the lower flange decreases the basic eigenfrequencies and critical loads computed in the linear elastic model. This reduction is very sensitive to the modeling accuracy and material model - especially for the first eigenvalue and buckling load; the results obtained in the third model keep much closer to these calculated with the girder without a fire.

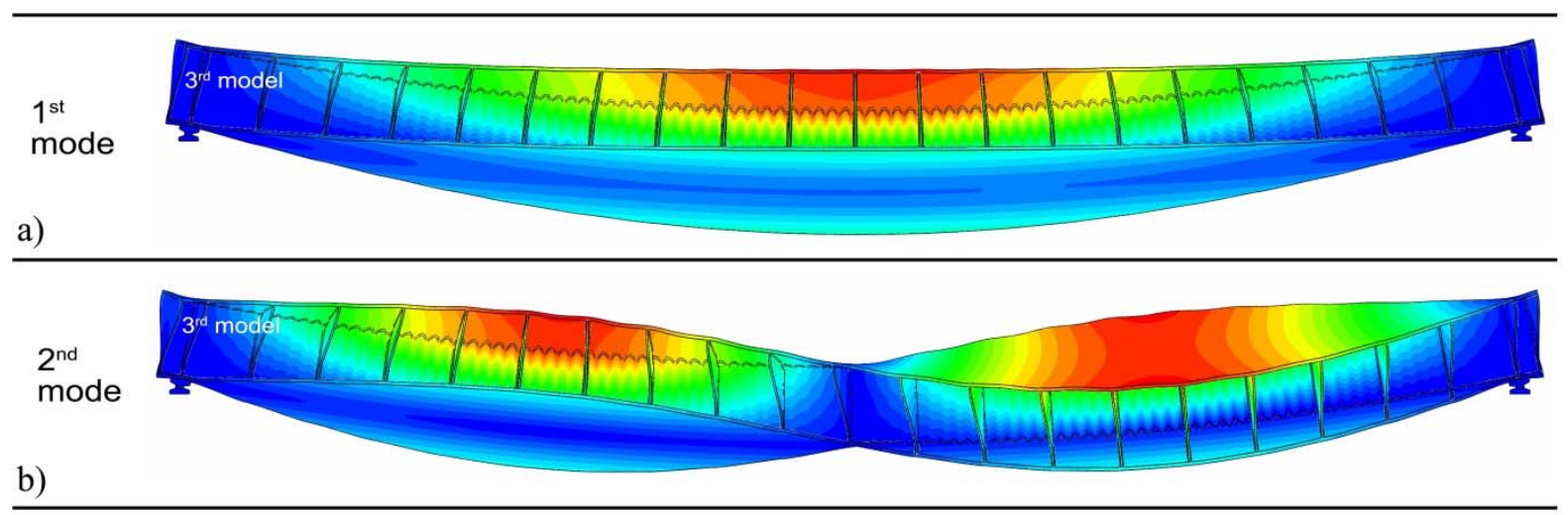

Fig.13. The 1st (a) and 2nd (b) buckling modes in the fire event after 180 min of the fire exposition.

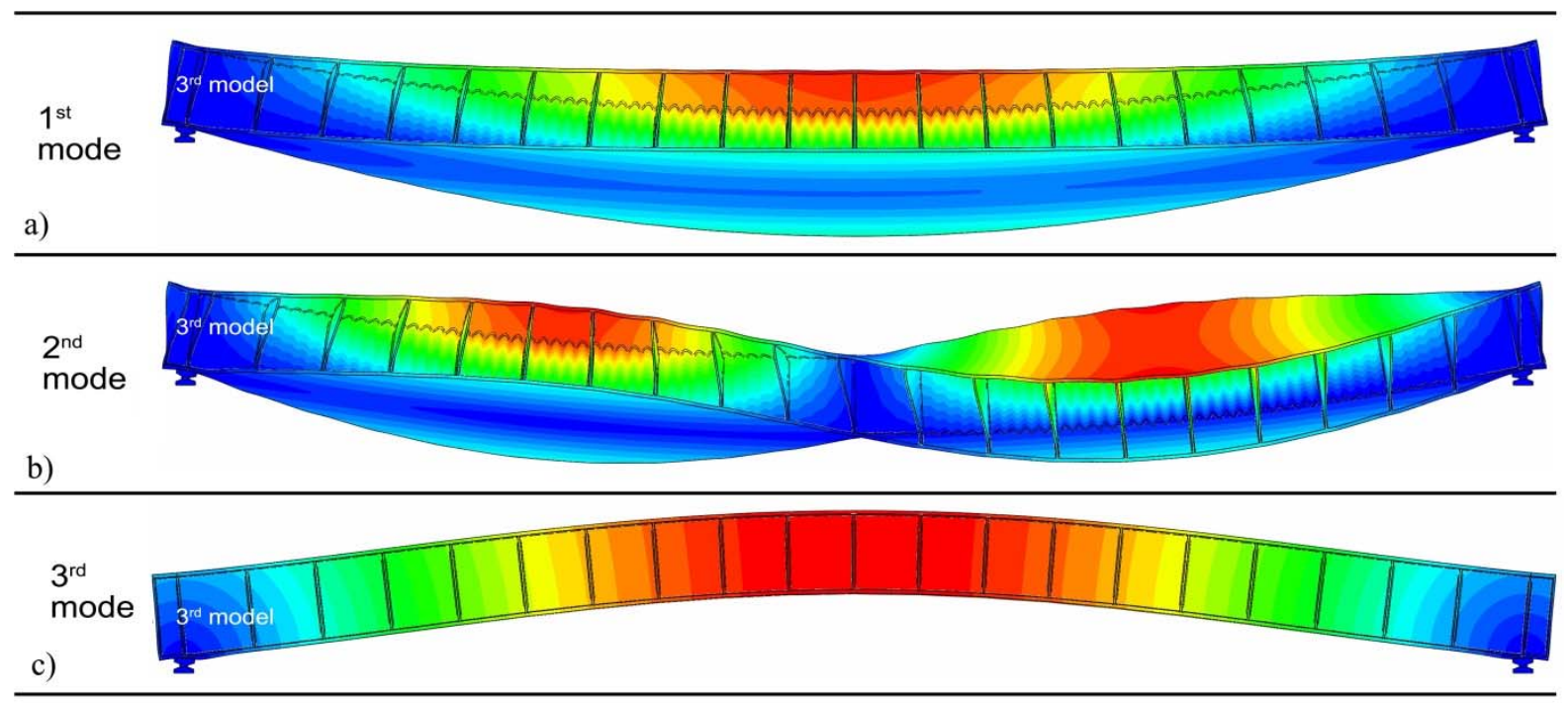

Fig.14. The $1^{\text {st }}(\mathrm{a}), 2^{\text {nd }}(\mathrm{b})$ and $3^{\text {rd }}(\mathrm{c})$ eigenfrequency modes in the fire event after $180 \mathrm{~min}$ of the fire exposition.

Figure 13 presents the buckling modes of the $3^{\text {rd }}$ transient model in the fire event after 180 min of the fire exposition - Fig.13.a for the $1^{\text {st }}$ buckling mode and Fig.13. (b) of the $2^{\text {nd }}$ buckling mode. They both are global modes of lateral-torsional type; the $1^{\text {st }}$ one with two nodes at the girder supports and the $2^{\text {nd }}$ with an additional node placed on the girder mid-span. Figure 14 presents eigenfrequency modes in the fire event after $180 \mathrm{~min}$ of the fire exposition for the $3^{\text {rd }}$ transient model, where Fig.14a presents the $1^{\text {st }}$, Fig. $14 \mathrm{~b}$ the $2^{\text {nd }}$ and Fig. 14c the third mode. Similarly to the buckling modes, the first two of them are rotational (twisting), while the $3^{\text {rd }}$ one preserves vibrations in the vertical direction. Quite importantly, values of the buckling load and eigenfrequencies determined for the most deformed geometry after the fire are very close to the steady state results (see Tab.2). Therefore, even extensive fire according to the given scenario does not introduce any danger related to resonance or accidental stability loss in this heated girder structure. 


\section{Conclusions}

Several non-linear FEM analyses of the simply supported corrugated web girder have been presented and discussed in this work. It reports the stress and deformation distributions as well as the basic buckling and eigenfrequency modes; it also presents fluctuations of state functions during 180 minutes of a permanent fire exposition. The girder was made of high strength steel under transient conditions resulting from an exposition of its lower flange to the Eurocode fire model. Selected FEM models of the girder have been meshed with different geometrical accuracy of the supports (full restraining of the degrees of freedom versus profiled steel plates) and various constitutive models - from linear elasticity up to experimental temperaturedependent elasto-plasticity.

Computational FEM results agree rather well with the analytical models and material nonlinearity has a limited importance under steady state conditions of the given ambient temperature. Such a conclusion is valid for the transient analysis of the structure exposed to fire, which quite early enters plastic hardening for the high strength steel such as S460. The results of this analysis show first that material characterization in increased temperatures is critically important and may lead to important variations of the computational failure time and also variation of the entire stress state including its magnitude and distribution. An introduction of the stress softening rule dramatically reduces the extreme temperature that the girder could sustain, while the perfect plasticity rule allows for the high rate of stress redistribution without loss of solver convergence.

A comparison of the results of the steady state and transient analysis shows that the stress and displacement distributions are completely different at ambient temperature and upon 180 minutes of fire exposition, which is not the case for eigenfrequencies and buckling loads, which are comparable. The reason of these differences is a temperature-induced material softening, which first of all results in a strong redistribution of stresses in fire conditions and, secondly, it increases many times the extreme vertical deflection. A distribution of the stresses follows directly the assumed fire scenario (exposition of the bottom flange to normative fire), the same concerns vertical displacements, which quite early (after a few minutes only) are larger than their admissible counterparts. A fire exposure also significantly increases the remaining stress tensor components, primarily in the web; they are no longer so marginal as for the steady temperature state at $20^{\circ} \mathrm{C}$. The basic eigenfrequencies and buckling modes are not so much affected by the fire, even after 180 minutes - some variations concern their magnitudes but the modes remain the same. It should be mentioned here that the fire boundary conditions are much simplified in comparison to the real fire event, when the fire could partially affect the girder web and modify the boundary as well as initial conditions. On the other hand, such simplified conditions may well serve for definition of the worst case scenario for steel segmental ceiling (where only the bottom flange is directly heated) or in cases when the fire exists solely beneath the girder under the bridge.

The simplified geometry linear models of this corrugated-web girder (the $1^{\text {st }}$ models in ambient and transient analyses) are precise enough for a simplified static analysis of its ULS and SLS including prediction of $\sigma_{22}, \sigma_{23}$ and $u_{3}$ in places advised by the strength of materials and also for the determination of its first critical load. However, they are completely inefficient in transient analyses, in the determination of eigenfrequencies and for a detailed consideration of entire stress maps in statics - especially their ultimate values and stresses in the welds. Insertion of a detailed support geometry in statics (the $3^{\text {rd }}$ model) improves the stress results and prevents erroneous stress amplification in the support region, but it still does not suffice for a transient analysis when the linear material is assumed. It is not recommended to apply the constitutive relation from Fig.4a for the transient fire analysis, because a strong softening induces convergence problems in the FEM regardless the step size and disallows a strong stress redistribution required in an elevated temperature.

\section{Nomenclature}

$$
\begin{array}{cl}
c(T) & - \text { specific heat } \\
E(T) & - \text { Young modulus } \\
f_{y}(T) & - \text { yield stress }
\end{array}
$$




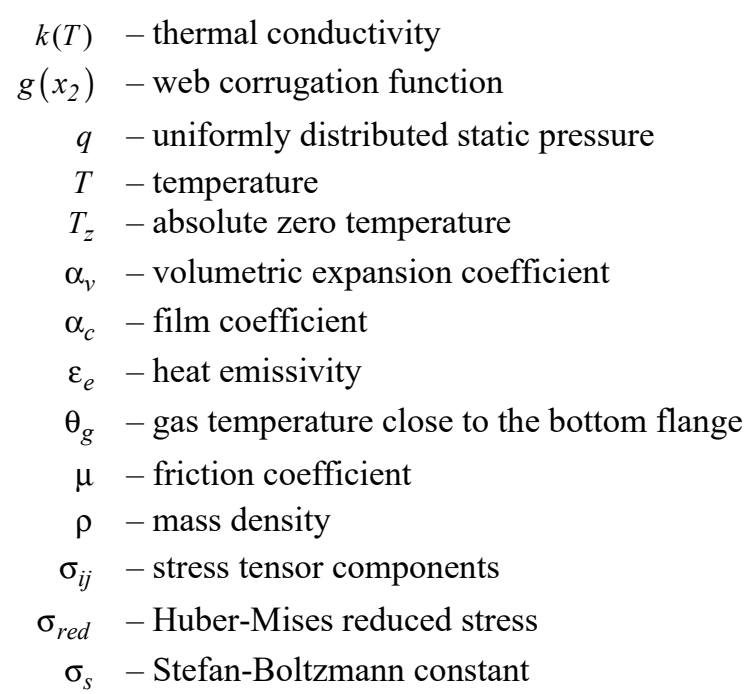

\section{References}

[1] Zirakian T., Lim J.B.P., Hajsadeghi M. and Bahrebar M. (2016): Structural performance of corrugated web steel coupling beams.- ICE Proceedings - Structures \& Buildings, vol.169, pp.756-764.

[2] Guo Y., Chen H., Pi Y., Dou C. and Bradford M.A. (2015): In-plane failure mechanism and strength of pin-ended steel Isection circular arches with sinusoidal corrugated web.- ASCE Journal of Structural Engineering, vol.142, pp.1-15.

[3] Aydın R., Yuksel E., Yardımcı N., HasimKısa M. and Gokce T. (2014): In-plane behavior of beam-to-column connections of corrugated web I-sections.- Journal of Constructional Steel Research, vol.100, pp.183-196.

[4] Guo Y.L., Chen H., Pi Y.L. and Bradford M.A. (2016): In-plane strength of steel arches with a sinusoidal corrugated web under a full-span uniform vertical load: Experimental and numerical investigations.- Engineering Structures, vol.110, pp.105-115.

[5] Wang Z., Tan L., Wang Q. (2013): Fatigue strength evaluation of welded structural details in corrugated steel web girders.- International Journal of Steel Structures, vol.13, pp.707-721.

[6] Huang L., Hikosaka H. and Komine K. (2004): Simulation of accordion effect in corrugated steel web with concrete flanges.- Computers and Structures, vol.82, No.23-26, pp.2061-2069.

[7] Kövesdi B., Jáger B. and Dunai L. (2012): Stress distribution in the flanges of girders with corrugated webs.Journal of Constructional Steel Research, vol.79, pp.204-215.

[8] Sayed-Ahmed E.Y. (2005): Plate girders with corrugated steel webs.- Engineering Journal, vol.42, No.1, pp.1-13.

[9] Easley J.T. and McFarland D.E. (1969): Buckling of light-gauge corrugated metal shear diaphragms.- Journal of Structural Division ASCE, vol.95, pp.1497-1516.

[10] Easley J.T. (1975): Buckling formulae for corrugated metal shear diaphragms.- Journal of Structural Division ASCE vol.101, pp.1403-1413.

[11] Elgaaly M. and Seshadri A. (1997): Girders with corrugated webs under partial compressive edge loading.Journal of Structural Engineering, vol.123, No.6, pp.783-791.

[12] Elgaaly M., Seshadri A. and Hamilton R.W. (1997): Bending strength of steel beams with corrugated webs.Journal of Structural Engineering ASCE, vol.123, No.6, pp.772-782.

[13] Li Y., Zhang W., Zhou Q., Qi X. and Widera G.E. (2000): Buckling strength analysis of the web of a WCW Hbeam: Part 2: development and research on H-beams with Wholly Corrugated Webs (WCW).- Journal of Material Processing and Technology, vol.101, No.1-3, pp.115-118.

[14] Driver R.G., Abbas H.H. and Sause R. (2006): Shear behavior of corrugated web bridge girders.- Journal of Structural Engineering, ASCE, vol.132, No.2, pp.195-203.

[15] Moon J., Yi J., Choi B.H. and Lee H.E. (2009): Shear strength and design of trapezoidally corrugated steel webs.Journal of Constructional Steel Research, vol.65, No.5, pp.1198-1205. 
[16] Pasternak H. and Kubieniec G. (2010): Plate girders with corrugated webs.- Journal of Civil Engineering and Management, vol.16, No.2, pp.166-171.

[17] He J., Liu Y., Lin Z., Chen A. and Yoda T. (2012): Shear behavior of partially encased composite I-girder with corrugated steel web: Numerical study.- Journal of Constructional Steel Research, vol.79, pp.166-182.

[18] Hassanein M.F. and Kharoob O.F. (2013): Behavior of bridge girders with corrugated webs: (II) Shear strength and design.- Engineering Structures, vol.57, pp.544-553.

[19] Hassanein M.F., Elkawas A.A., El Hadidy A.M. and Elchalakani M. (2017): Shear analysis and design of highstrength steel corrugated web girders for bridge design.- Engineering Structures, vol.146, pp.18-33.

[20] Leblouba M., Junaid M.T., Barakat S., Altoubat S. and Maalej M. (2017): Shear buckling and stress distribution in trapezoidal web corrugated steel beams.- Thin-Walled Structures, vol.113, pp.13-26.

[21] Riahi F., Behravesh A. and Fard M.Y. (2018): Shear buckling analysis of steel flat and corrugated Web I-girders.KSCE Journal of Civil Engineering, vol.22, No.2, pp.5058-5073.

[22] Zevallos E., Hassanein M.F., Real E. and Mirambell E. (2016): Shear evaluation of tapered bridge girder panels with steel corrugated webs near the supports of continuous bridges.- Engineering Structures, vol.113, pp.149-159.

[23] Elkawas A.A., Hassanein M.F. and El-Boghdadi M.H. (2017): Numerical investigation on the nonlinear shear behaviour of high-strength steel tapered corrugated web bridge girders.- Engineering Structures, vol.134, pp.358-375.

[24] El Hadidy A.M., Hassanein M.F. and Zhou M. (2018): The effect of using tubular flanges in bridge girders with corrugated steel webs on their shear behaviour - A numerical study.- Thin-Walled Structures, vol.124, pp.121-135.

[25] Wang S., He J., Liu Y., Li C. and Xin H. (2018): Shear capacity of a novel joint between corrugated steel web and concrete lower slab.- Construction and Building Materials, vol.163, pp.360-375.

[26] Wang S., Liu Y., He J., Xin H. and Yao H. (2019): Experimental study on cyclic behavior of composite beam with corrugated steel web considering different shear-span ratio.- Engineering Structures, vol.180, pp.669-684.

[27] Chan C.L., Khalid Y.A., Sahari B.B. and Hamouda A.M.S. (2002): Finite element analysis of corrugated web beams under bending.- Journal of Constructional Steel Research, vol.58, No.11, 1391-1406.

[28] Abbas H.H., Sause R. and Driver R.G. (2006): Behavior of corrugated web I-girders under in-plane loads.Journal of Engineering Mechanics, ASCE, vol.132, No.8, DOI: 10.1061/(ASCE)0733-9399(2006)132:8(806).

[29] Wang L. and Young B. (2017): Design of cold-formed steel built-up sections with web perforations subjected to bending.- Thin-Walled Structures, vol.120, pp.458-469.

[30] Jáger B., Dunai L. and Kövesdi B. (2017): Flange buckling behavior of girders with corrugated web Part I: Experimental study.- Thin-Walled Structures, vol.118, pp.181-195.

[31] Sayed-Ahmed E.Y. (2005): Lateral torsion-flexure buckling of corrugated web steel girders.- Proceedings of the Institution of Civil Engineers: Structures and Buildings, vol.158, No.1, pp.53-69.

[32] Kövesdi B., Jáger B. and Dunai L. (2016): Bending and shear interaction behavior of girders with trapezoidally corrugated webs.- Journal of Constructional Steel Research, vol.121, pp.383-397.

[33] Hassanein M.F. and Kharoob, O.F. (2013): Behavior of bridge girders with corrugated webs: (I) Real boundary condition at the juncture of the web and flanges.- Engineering Structures, vol.57, pp.554-564.

[34] Najjar S.R. and Burgess I.W. (1996): A nonlinear analysis for three-dimensional steel frames in fire conditions.Engineering Structures, vol.18, No.1, pp.77-89.

[35] Liew Y.R., Tang L.K., Holmaas T. and Chao Y.S. (1998): Advances analysis for the assessment of steel frames in fire.- Journal of Constructional Steel Research, vol.47, pp.19-45.

[36] Landesmann A., Batista E.M. and Alves J.L.D. (2005): Implementation of advances analysis method for steelframed structures under fire conditions.- Fire Safety Journal, vol.40, pp.339-366.

[37] Wald F., Simões da Silva L., Moore D.B., Lennon T., Chladná M., Santiago A., Beneš M. and Borges L. (2006): Experimental behaviour of a steel structure under natural fire.- Fire Safety Journal, vol.41, No.7, pp.509-522.

[38] Aziz E.M., Kodur V.K., Glassman J.D. and Moreyra Garlock M.E. (2015): Behavior of steel bridge girders under fire conditions.- Journal of Constructional Steel Research, vol.106, pp.11-22.

[39] Kodur V.K., Aziz E.M. and Naser M.Z. (2017): Strategies for enhancing fire performance of steel bridges.Engineering Structures, vol.131, pp.446-458. 
[40] Laím L. and Rodrigues J.P.C. (2018): Fire design methodologies for cold-formed steel beams made with open and closed cross-sections.- Engineering Structures, vol.171, pp.759-778.

[41] Qiang X. (2013): Experimental results of high strength steel endplate connections in fire and after fire.- Stevin Report 6-13-1, Delft University of Technology.

[42] Zhang C., Silva J.G., Weinschenk C., Karnikawa D. and Hasemi Y. (2016): Methodology for coupled fire-structure analysis: modeling localized fire tests on a steel column.- Fire Technology, vol.52, pp.239-262.

[43] Vácha J., Kyzlík P., Both I and Wald, F. (2016): Beams with corrugated web at elevated temperature, experimental results.- Thin-Walled Structures, vol.98, pp.19-28.

[44] Wang Z.Y., Wang Q.Y. and Jiang R.J. (2015): Finite element based fatigue assessment of corrugated steel web beams in highway bridges.- International Journal of Civil Engineering, vol.13, pp.419-431.

[45] Wang P., Liu C., Liu M. and Wang X. (2016): Numerical studies on large deflection behaviour of axially restrained corrugated web steel beams at elevated temperatures.- Thin-Walled Structures, vol.98, pp.58-74.

[46] Wang P., Liu C. and Liu M. (2016): Large deflection behavior of restrained corrugated web steel beams in a fire.Journal of Constructional Steel Research, vol.126, pp.92-106.

[47] Chen S.H., Han Y.L. and Zhang, J.H. (2011): Elastic shear bucking analysis of corrugated web steel beam in the fire.-Advanced Materials Research, vol.255-260, pp.534-538.

[48] Maslak M.M. and Lukacz M. (2017): Interactive shear resistance of corrugated web in steel beam exposed to fire.- Journal of Structural Fire Engineering, vol.7, No.1, pp.69-78.

49] Vácha J., Kyzlík P., Both I. and Wald, F. (2016): Beams with corrugated web at elevated temperature, analytical and numerical models for heat transfer.- Fire Safety Journal, vol.86, pp.83-94.

[50] Sokołowski D., Kamiński M. and Strąkowski M. (2014): Stochastic Finite Element Method reliability analysis of the corrugated I-beam girder.- CMES: Computer Modeling in Engineering \& Sciences, vol.99, pp.209-231.

Received: September 16, 2020

Revised: January 13, 2021 